\title{
Microdialysis: Is it ready for prime time?
}

\author{
J. Clay Goodman, M.D., F.A.A.N. [Associate Dean for Undergraduate Medical Education \\ and Professor] and \\ Departments of Pathology, Neurology and Neurosurgery, Baylor College of Medicine, Houston, \\ TX 77030
}

Claudia S. Robertson, M.D. [Professor]

Department of Neurosurgery, Baylor College of Medicine, Houston, TX 77030

\begin{abstract}
Purpose of review-This review highlights recent advances in cerebral microdialysis for investigational and clinical neurochemical monitoring in patients with critical neurological conditions.
\end{abstract}

Recent findings-Use of microdialysis with other methods including positron emission tomography, electrophysiological monitoring and brain tissue oximetry in traumatic brain injury (TBI), subarachnoid hemorrhage (SAH) with vasospasm, and infarction with refractory increased intracranial pressure have been reported. Potentially adverse neurochemical effects of nonconvulsive status epilepticus and cortical slow depolarization waves both of which are increasingly recognized in TBI and stroke patients have been reported. The explosive growth in the use of cerebral oximetry with targeted management of brain tissue oxygen levels is leading to greater understanding of derangements of cerebral bioenergetics in the critically ill brain, but there remain unresolved basic issues. Understanding of the analytes that are measurable at the bedside glucose, lactate, pyruvate, glutamate and glycerol - continues to evolve with glucose, lactate, pyruvate and the lactate/pyruvate $(\mathrm{L} / \mathrm{P})$ ratio taking center stage. Analytes including inflammatory biomarkers such as cytokines and metabolites of nitric oxide are presently investigational, but hold promise for future application in advancing our understanding of basic pathophysiology, therapeutic target selection and prognostication. Growing consensus on indications for use of clinical microdialysis and advances in commercially available equipment continue to make microdialysis increasingly "ready for prime time."

Summary-Cerebral microdialysis is an established tool for neurochemical research in the intensive care unit. This technique cannot be fruitfully used in isolation, but when combined with other monitoring methods provides unique insights into the biochemical and physiological derangements in the injured brain.

\section{Keywords}

brain injury; neurochemical monitoring; microdialysis; traumatic brain injury; subarachnoid hemorrhage

\section{Introduction}

Cerebral microdialysis was introduced for basic studies almost 40 years ago and has been used clinically for neurochemical monitoring in the intensive care unit since 1992[1,2].

Corresponding Author: J. Clay Goodman, M.D., F.A.A.N., Associate Dean for Undergraduate Medical Education and Professor, Departments of Pathology, Neurology and Neurosurgery, Baylor College of Medicine MS: BCM 315, Houston, TX 77030, Phone: 713-798-7234,jgoodman@bcm.tmc.edu. 
Several excellent reviews have appeared in recent years [••3-18]. Some are definitive and detailed while others are more terse but accessible and informative. In addition, a comprehensive handbook of microdialysis has been published[ $\bullet \cdot 19]$. Cerebral microdialysis was last reviewed in this journal in $2006[\bullet 20]$, and the purpose of the current communication is to review and synthesize new contributions on microdialysis in acute brain injury predominantly from 2007 through 2008 with some consideration of this technique's readiness for routine application in the intensive care unit.

\section{Neurochemical mechanisms of acute brain injury studied using microdialysis}

Microdialysis analytes available at the bedside can provide information about brain bioenergetics, excitatory amino acid release, and membrane integrity[3-6,9,11-14,17,2125]. Glucose, pyruvate and lactate measurements provide information about the relative contributions of aerobic and anaerobic metabolism to bioenergetics. Glutamate measurement provides insight into the excitatory amino acid milieu of the brain and since amino acids are released uncontrollably during energy failure, this amino acid also serves as a marker of bioenergetic insufficiency. Glycerol is released by the enzymatic cleavage of cellular membrane triglycerides and indicates cellular distress including energy failure. In the past two years, microdialysis work has emerged defining the range of bioenergetic disturbances in acute brain injury, the contribution of cortical electrical disturbances including nonconvulsive status epilepticus and cortical spreading depolarizations to neurchemical distress, and several novel analytes with translational potential have been investigated.

Bioenergetics can be evaluated by examining the availability of fuel - glucose - that may be metabolized aerobically in the tricarboxylic acid cycle to produce carbon dioxide and water with a high adenosine triphosphate (ATP) yield. Alternatively, glucose may be metabolized anaerobically via glycolysis to produce lactate with a miserable ATP yield. Pyruvate is at the terminus of glycolysis and at the entry point of the tricarboxylic acid cycle. Lactate concentration elevation and elevation of the lactate/pyruvate $(\mathrm{L} / \mathrm{P})$ ratio are robust and reliable indicators of increased anaerobic metabolism. A shift to anaerobic metabolism may result from ischemia or hypoxia where the substrates necessary to sustain aerobic metabolism are simply not available or when there is failure of mitochondria oxidative phosphorylation. Ischemia has been well documented in TBI with an adverse impact of morbidity and mortality [26,27]. Ischemia may occur due to inadequate CPP, increased ICP or systemic disorders leading to inadequate perfusion, ventilation or oxygen carrying capacity[28]. Episodes of ischemia can be documented using microdialysis and the quantitative impact on bioenergetics measured [3,9,11,12,29-59]. Many investigators have shown that the tissue at greatest risk (and with the greatest potential for salvage) is the pericontusional tissue in TBI and vascular territory in SAH. Probes placed directly in contusions or infarcts reveal severe neurochemical alterations indicative of irreversible damage. If a discrete lesion is not present, probe placement in a relatively silent region such as the right frontal lobe, can provide insight into cerebral bioenergetics.

In acute brain injury, bioenergetic pertubations characterized by diminished pyruvate concentration without hypoxia leading to an elevated L/P ratio as been described[ $\bullet \cdot 57,60]$. This form of "non-ischemic" elevated L/P ratio has been designated type 2 elevation while conventional ischemic elevation is type $1[20]$. This neurochemical anomaly may reflect impairment of the glycolytic pathway itself or inadequate availability or entry of glucose into the pathway possible due to shunting of glucose to competing pathways such as the pentose phosphate pathway that has been described in clinical TBI[•61]. Such decreased metabolic flux through the glycolytic pathway compromises both anerobic and aerobic metabolism, and may pose a bioenergetic threat to the brain. Regardless of mechanism, 
decreased glucose concentration in microdialysate samples is a poor prognostic indicator $[\bullet 62]$.

Generalized convulsive seizures are recognizable in the ICU, however, the high frequency of non-convulsive seizures and non-convulsive status epilepticus was not recognized until recently using continuous electroencephalographic monitoring. These seizures are associated with elevated $\mathrm{L} / \mathrm{P}$ ratios and increased intracranial pressure $[57, \bullet 63, \bullet \bullet 64]$. This may be a situation in which increased tissue energy demand may not be adequately met. Seizure recognition and control as well as hypothermia would reduce metabolic demand.

Another electrical disturbance receiving increased attention is cortical spreading depolarization (CSD). First described in 1944 by Leão, these waves of cortical depolarization spread across the cortical surface at 2-3 $\mathrm{mm} /$ minute with immediately afterfollowing hyperemia. The human neocortex was thought to be resistant to this phenomenon, but recent work in migraine, TBI and stroke has established CSD as a common and potentially pathogenic occurrence[••65-69]. CSD occurs in up to 50\% of patients with severe TBI and 50-70\% of patients with infarcts. Neurochemical events accompanying CSD have been studied using rapid sequence microdialysis (rsMD) that is an investigational technique using on-line flow injection analysis of glucose and lactate over a time scale of seconds representing a major improvement in temporal resolution over conventional microdialysis. In a series of elegant papers, rsMD as demonstrated marked glucose depletion and lactate elevation occurring in the hyperemic phase of CSD's. The severity of glucose depletion is proportional to the number of depolarizations and the authors propose that a visous cycle may be initiated in which CSD's lead to glucose depletion and bioenergetic distress which may beget additional depolarization waves [••70-72].

Novel analytes have recently received increased attention including cytokines, nitric oxide metabolites and $\mathrm{N}$-acetylaspartate (NAA). Cytokines are proteins that exert a broad range of physiological effects. An individual cytokine may have multiple effects but generally these compounds are either pro-inflammatory or anti-inflammatory. The eventual inflammatory state of the tissue depends of the complex interplay of multiple cytokines. Initial studies were performed in serum and cerebrospinal fluid, but cytokines have now been measured in microdialysates in animals and humans [•73-77]. In Hillman's study, paired intracerebral microdialysis catheters with high-cutoff membranes were inserted in 14 comatose patients with subarachnoidal hemorrhage or TBI. Macroscopic tissue injury was strongly linked to IL- 6 but not IL- $1 b$ activation, and IL release appeared to be stimulated by local ischemia. Hutchinson studied 15 TBI patients and found no significant relationships between IL-1 alpha and beta, IL-1 receptor (IL-1ra) and energy-related molecules. There was a significant correlation between increasing IL-1beta and increasing IL-1ra, and increasing IL-1 ra with decreasing intracranial pressure. High concentrations of IL-1 ra and high IL-1ra/IL-1beta ratio were associated with better outcome. Mellergard and colleagues measured the concentration of interleukin (IL)-1 beta, IL-6, IL-8, macrophage inflammatory protein-1 beta, regulated on activation, normal T-cell expressed and secreted (RANTES), fibroblast growth factor-2, and vascular endothelial growth factor was determined by a multiplex assay, and IL-10 was determined by enzyme-linked immunosorbent assay in 38 patients.

Nitrate and nitrite are the oxidative metabolites (NOx) of nitric oxide (NO), a gaseous neurotransmitter that contributes to regulation of vascular tone, neuronal communication and inflammation. NO may be helpful in acute brain injury by maintaining cerebrovascular reactivity but at higher concentrations such as those seen in inflammation could be detrimental; therefore, measurement of NOx has received attention. Low NOx concentrations correlate with decreased cerebral blood flow, diminished cerebrovascular 
reactivity and poor outcome in TBI and SAH [78-81]. Instrumentation suitable for NOx measurement in the ICU is available but is not widely used in neurocritical care.

$\mathrm{N}$-Acetylaspartate (NAA) is a neuronal marker present in high concentration in the CNS that can be measured by proton magnetic resonance spectroscopy and NAA depletion is a marker of neuronal damage and death. Belli and colleagues investigated 19 patients with TBI using microdialysis to recover NAA, lactate, pyruvate, glycerol and glutamate, and showed that NAA was 34\% lower in non-survivors[82]. A non-recoverable fall in NAA was observed in non-survivors beyond day 4 with a concomitant rise in lactate-pyruvate ratio and glycerol suggesting bioenergetic failure contributed to the poor outcome.

\section{Does microdialysis have a role in clinical decision-making in the critical care unit?}

Microdialysis is one of several techniques used in monitoring the critically ill patient. In order to impact clinical decision making, monitoring should allow detection of pathophysiological events, provide guidance so that targeted therapy can be deployed and allow assessment of effects of therapy. Monitoring may also provide prognostic information that may guide decisions about the appropriate intensity and duration of therapy.

Glycerol results from the enzymatic degradation of membrane triglycerides and indicators loss of cellular structural integrity. [83-87]. Belli et al reported that a L/P ratio $>25$ and glycerol >100 micromole/L, were associated with significantly higher risk of imminent intracranial hypertension, but glutamate $>12$ micromole/L was not predictive. An abnormal $\mathrm{L} / \mathrm{P}$ ratio was predictive of an ICP rise above normal levels in $89 \%$ of cases. These changes occurred before the onset of intracranial hypertension, suggesting that biochemical impairment may occur before low cerebral perfusion pressure is detectable; therefore, $\mathrm{L} / \mathrm{P}$ ratio and glycerol elevations may be early warning signals of imminent deterioration $[\bullet 88]$.

Glutamate, the major excitatory amino acid in the brain, is critical for physiological signaling and long-term potentiation. Uncontrolled release is seen in experimental and clinical TBI and ischemia, but this biomarker may be a relatively late indicator of dysfunction and has not been a major focus of investigation in the past two years. Astrocytic uptake keeps brain interstitial glutamate levels low. Astrocytes convert glutamate to glutamine that is released and reconverted to glutamate in neurons. This cycle is energy demanding and impaired energy metabolism may lead to low interstitial glutamine/ glutamate ratios. Using microdialysis measurements from noninjured cortex in 33 patients with SAH, investigators found lactate/pyruvate (L/P) ratios correlated to the glutamine/ glutamate ratios but the correlation was no stronger than the correlation between L/P or lactate and glutamate alone. During periods of bioenergetic crisis indicated by $\mathrm{L} / \mathrm{P}$ ratios above 40 there were high interstitial glutamate levels. In periods with L/P ratios above 40 with low pyruvate levels, interstitial glutamine levels were decreased, suggesting ischemia and failing astrocytic glutamine synthesis. Periods with L/P ratios above 40 and normal or high pyruvate levels were associated with increased glutamine levels, possibly indicating an astrocytic hyperglycolytic response to high interstitial glutamate levels. Moderately elevated $\mathrm{L} / \mathrm{P}$ ratios cannot always be interpreted as failing energy metabolism, and pyruvate levels may discriminate whether or not there is sufficient astrocytic capacity for glutamate/ glutamine cycling in the brain [• 89]. While general ICU patients experience reduced mortality and morbidity when nutritionally supplemented with intravenous glutamine, there has been reluctance to use glutamine supplementation in neurosurgical patients for fear of elevating intracerebral glutamate levels. Berg el al studied 15 TBI patients receiving glutamine infusions that increased plasma glutamine concentration by $30 \%$, but no plasma or intracerebral glutamate were observed, suggesting this nutritional supplementation may 
be an option in the neurointensive care [90]. Miller et al studied interstitial glutamate in intracerebral hemorrhage (ICH) in 12 consecutive patients undergoing Frameless Stereotactic Aspiration and Thrombolysis (FAST) of deep ICH's. Glucose, lactate, pyruvate, and glutamate were measured in the perihematomal tissue of patients undergoing minimally invasive hematoma evacuation. Brain hematoma volumes were reduced $87 \%$ during FAST and National Institute of Health Stroke Scale (NIHSS) scores were improved from an average of 19 at admission to 12.6 at time of discharge. Glutamate average values decreased from the first 24 hours of measurement $(12 \mathrm{mmol} / \mathrm{L}+/-6)$ to the final 24-hour epoch $(5$ $\mathrm{mmol} / \mathrm{L}+/-6$ ). Ischemic $\mathrm{L} / \mathrm{P}$ ratios were not found in peri-hematomal regions and were unchanged during hematoma drainage. The authors suggest that excitotoxicity related to glutamate may have an important impact in $\mathrm{ICH}$, but that ischemia may have little role in secondary peri-hematomal damage $[\bullet 91]$.

Many experimental studies have demonstrated improvement in microdialysate neurochemical parameters with hypothermia and several series have been reported in critically ill patients [31,42,92-97]. Berger reported an open, prospective observational study in 24 patients with large MCA infarction undergoing either hypothermia (33 degrees C), hemicraniectomy, or maximum conservative therapy with probe placement in the periinfarct tissue within 24 hour after stroke onset. Glutamate concentrations in patients treated with hemicraniectomy $(5.3+/-0.5 \mathrm{mumol})$ and hypothermia $(14.5+/-3.6 \mathrm{mumol} / \mathrm{l})$ were significantly lower than in conservatively treated patients $(68.3+/-5.2 \mathrm{mumol} / \mathrm{l})$. Glycerol concentrations were lower in patients treated by hypothermia $(111+/-17 \mathrm{mumol} / \mathrm{l})$ and hemicraniectomy $(138+/-8 \mathrm{mumol} / \mathrm{l})$ compared to conservatively treated patients with 612 $+/-27 \mathrm{mumol} / \mathrm{l}$. The lactate-pyruvate ratio was lower both in the hypothermia $(16.2+/-3.3)$ and hemicraniectomy groups $(31.3+/-1.5)$ than in the conservative treatment group $(56+/-$ 2.9). Wang et al studied the effect of mild hypothermia on glucose metabolism and glycerol in 31 TBI patients with probes inserted into perilesional and normal brain tissue. In the hypothermia group, lactate/glucose ratio(L/G), lactate/pyruvate ratio(L/P) and glycerol in perilensional tissue were all decreased, and the $\mathrm{L} / \mathrm{P}$ ratio in normal brain tissue was decreased. In normothermia, $\mathrm{L} / \mathrm{G}, \mathrm{L} / \mathrm{P}$ and glycerol in perilensional tissue were higher than that in normal brain tissue. Mild hypothermia appears to protect brain tissues by decreasing $\mathrm{L} / \mathrm{G}, \mathrm{L} / \mathrm{P}$ and glycerol in peri-lesional tissue and $\mathrm{L} / \mathrm{P}$ in "normal brain" tissues. Bioenergetic crisis and membrane phospholipid degradation in peri-lensional tissue are impacted to a greater degree by hypothermia than derangements in normal cerebral tissue[87].

The increased use of cerebral oximetry and the demonstrated adverse impact of hypoxia on ICP, cerebral bioenergetics and outcome led to increased interest in hyperoxia in TBI. Tisdal and colleagues used brain tissue oxygen tension measurement, cerebral microdialysis, and near-infrared spectroscopy to study the effects of normobaric hyperoxia in 8 adults with TBI within the first 48 hours postinjury. Inspired oxygen at normobaric pressure was increased from baseline to $60 \%$ for 1 hour and then to $100 \%$ for 1 hour before being returned to baseline for 30 minutes. When inspired oxygen was $100 \%$, brain tissue oxygen tension increased by $7.2 \mathrm{kPa}$, microdialysate lactate concentration decreased by $0.26 \mathrm{mmol} / \mathrm{L}$, microdialysate $\mathrm{L} / \mathrm{P}$ ration decreased by 1.6 . No significant changes in intracranial pressure or arterial or microdialysate glucose concentration were seen [•98]. In contrast, Nortje et al studied eleven patients with severe TBI using microdialysis, brain tissue oximetry, and oxygen-15 positron emission tomography (15O-PET) during normoxia and hyperoxia ( $\mathrm{FiO} 2$ increase of between 0.35 and 0.50). Hyperoxia increased mean $\mathrm{PbO} 2$ from $28+/-21 \mathrm{~mm}$ $\mathrm{Hg}$ to $57+/-47 \mathrm{~mm} \mathrm{Hg}(\mathrm{p}=.015)$. Microdialysate lactate and pyruvate were unchanged, but the lactate/pyruvate ratio showed a statistically significant reduction $(34.1+/-9.5 \mathrm{vs}$. $32.5+/-9.0, \mathrm{p}=.018$ ), but the magnitude of reduction was small, and the authors concluded that its clinical significance was doubtful[••99]. In a recent review, Diringer suggests that 
additional studies are appropriate but that routine clinical use of hyperoxia is not currently warranted particularly in view of potentially harmful effects of this therapy[••100].

Hyperglycemia has been shown in multiple studies to be an unfavorable prognostic indicator in TBI, stroke and sepsis resulting in interest in rigorous glycemic control using insulin in critically ill patients. Two important recent papers using cerebral microdialysis challenge the utility of "tight" glycemic control. Vespa et al in 2006 reported 14 patients treated with rigorous insulin therapy had a reduction in microdialysis glucose by $70 \%$ of baseline concentration compared with a $15 \%$ reduction in 33 patients treated with a more relaxed insulin protocol[101]. Additionally, intensive insulin therapy was associated with increased occurrence of elevated glutamate $(38+/-37 \%$ vs. $10+/-17 \%)$, elevated lactate/pyruvate ratio $(38+/-37 \%$ vs. $19+/-26 \%)$ and low glucose $(26+/-17 \%$ vs. $11+/-15 \%)$. Mortality was similar in the intensive and loose insulin treatment groups. More ominously, in a study of ICU patients in which glycemic was "tight" (4.4-6.7 mmol/L [80-120 mg/dL]) vs. "intermediate" (6.8-10.0 mmol/L [121-180 mg/dL]) range, tight systemic glucose levels were associated with a greater prevalence of low cerebral microdialysis glucose $(65 \%$ vs. $36 \%$ ) and brain energy crisis (25\% vs. $17 \%$ ) than intermediate levels. Adjusting for intracranial pressure and cerebral perfusion pressure, systemic glucose concentration and insulin dose independently predicted brain energy crisis. Cerebral microdialysis glucose was lower in nonsurvivors than in survivors and brain energy crisis was associated with

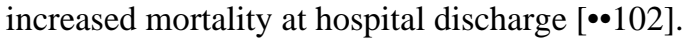

In an important study, Marcoux reported that the L/P ratio in the first 4 days after trauma to allowed prediction of frontal brain atrophy at 6 months after injury. The lactate/pyruvate ratio was elevated $>40$ after for $32+/-29 \%$ of the mean percent time of monitored. At 6 months, the percentage of time of elevated lactate/pyruvate ratio correlated with the degree of frontal lobe brain atrophy, but not with global brain atrophy. This predictive effect of lactate/pyruvate ratio was independent of patient age, Glasgow Coma Scale score, and volume of frontal lobe contusion $[\bullet 103]$.

In 2004 a conference of clinical microdialysis experts was convened to reach consensus on the clinical indications for deployment of microdialysis [104]. This panel recommended that microdialysis be considered in TBI and SAH patients requiring ICP and CPP monitoring. The battery of glucose, pyruvate, lactate, glycerol and glutamate was recommended with use of the calculated $\mathrm{L} / \mathrm{P}$ ratio. An important outcome of the meeting was consensus on the site of probe placement. In TBI, placement in peri-contusional at risk tissue, was recommended and if the option for placement of a second probe is available, that probe should be placed in normal tissue. It was agreed that placement directly into contusions was of no value. In cased of diffuse injury, probe placement should be in the right frontal lobe. In SAH, the probe should be placed in the parent vessel's territory. In 2008, another consensus conference was convened, this time of intensivists and emergency physicians rather than microdialysis experts. This panel was more conservative and did not give specific recommendations on use of clinical microdialysis while lamenting the absence of Class I trials demonstrating the utility of microdialysis while acknowledging the scientific validity of the technique[$[105]$.

\section{Advances in methodology}

Several methodological advances have been made in the last two years. The practical implementation of microdialysis in the intensive care unit continues to be dependent on the introduction of commercially available instrumentation. The introduction of the CMA600 bedside analyzer markedly accelerated both investigational and clinical applications of microdialysis. The next generation instrument, the CMA ISCUS ${ }^{\text {flex }}$ was introduced in late 
2008 (CMA/Microdialysis, Solona, Sweden). Like its predecessor, this instrument uses enzymatic reagents and colorimetric measurement, but is substantially smaller, has batch processing capability, and permits monitoring and time trend display of neurochemical data on up to eight patients. Glucose, pyruvate, lactate, glycerol, glutamate and urea are the available analytes. The same company has recently released software (ICUpilot) that allows interfacing with other monitoring equipment so that physiological and neurochemical data can be displayed on several commonly used ICU information systems. For several years, the primary commercially available brain microdialysis catheter was the CMA 70 Brain MD Catheter with a relatively low molecular weight cut-off, $20 \mathrm{kDa}$. The CMA 71 High Cut-Off Brain Microdialysis Catheter has a molecular weight range up to $100 \mathrm{kDa}$ that is more suitable for sampling larger molecules such as cytokines. At present, CMA-71 probes are not FDA-approved and must be used under a research protocol in the US Modifications of the lower molecular weight cut-off probe are also available to facilitate use with cranial bolts that permit placement of multiple probes and sensors.

\section{Conclusion}

Cerebral microdialysis continues to provide substantial new information about the neurochemistry of the acutely injured brain. Mechanistic insights have already been translated to clinical application through increased attention to CPP, tissue oxygenation, vigilance for cortical electrical disturbances and judicious application of mild hypothermia. We can anticipate that use of microdialysis in clinical investigation will continue to provide valuable mechanistic information and therapeutic options. The "routine" application of microdialysis is within the reach of technically advanced intensive care units where this technique must be used in conjunction with other methods to provide true multi-modality monitoring of the critically ill patient.

\section{Acknowledgments}

We gratefully acknowledge the contributions of the house staff, research fellows, research assistants and nurses of the Ben Taub General Hospital Neurosurgical Intensive Care Unit. This review is dedicated to our wonderful colleague, Dr. Roman Hlatky, whose short but extremely productive life ended in 2006 in an automobile accident involving an intoxicated driver. Research funding support from the National Institutes of Health P01 Grant \#NS38660.is gratefully acknowledged.

\section{References}

1. Persson L, Hillered L. Chemical monitoring of neurosurgical intensive care patients using intracerebral microdialysis. J Neurosurg. 1992; 76:72-80. [PubMed: 1727172]

2. Hillered L, Persson L, Ponten U, Ungerstedt U. Neurometabolic monitoring of the ischaemic human brain using microdialysis. Acta Neurochir (Wien). 1990; 102:91-97. [PubMed: 1970920]

$\bullet$ 3. Hillered L, Vespa PM, Hovda DA. Translational neurochemical research in acute human brain injury: the current status and potential future for cerebral microdialysis. J Neurotrauma. 2005; 22:3-41. Definitive review article on microdialysis in translational research up to 2005. [PubMed: 15665601]

4. McAdoo DJ, Wu P. Microdialysis in central nervous system disorders and their treatment. Pharmacol Biochem Behav. 2008; 90:282-296. [PubMed: 18436292]

5. Helmy A, Carpenter KL, Hutchinson PJ. Microdialysis in the human brain and its potential role in the development and clinical assessment of drugs. Curr Med Chem. 2007; 14:1525-1537. [PubMed: 17584061]

-6. Tisdall MM, Smith M. Cerebral microdialysis: research technique or clinical tool. Br J Anaesth. 2006; 97:18-25. Brief but authoritative review of cerebral microdialysis. [PubMed: 16698861]

7. Rooyackers O. Microdialysis to investigate tissue amino acid kinetics. Curr Opin Clin Nutr Metab Care. 2005; 8:77-82. [PubMed: 15586004] 
8. Plock N, Kloft C. Microdialysis--theoretical background and recent implementation in applied lifesciences. Eur J Pharm Sci. 2005; 25:1-24. [PubMed: 15854796]

9. Hutchinson PJ. Microdialysis in traumatic brain injury--methodology and pathophysiology. Acta Neurochir Suppl. 2005; 95:441-445. [PubMed: 16463898]

10. Rooyackers O, Thorell A, Nygren J, Ljungqvist O. Microdialysis methods for measuring human metabolism. Curr Opin Clin Nutr Metab Care. 2004; 7:515-521. [PubMed: 15295271]

11. Sarrafzadeh AS, Kiening KL, Unterberg AW. Neuromonitoring: brain oxygenation and microdialysis. Curr Neurol Neurosci Rep. 2003; 3:517-523. [PubMed: 14565908]

12. Peerdeman SM, van Tulder MW, Vandertop WP. Cerebral microdialysis as a monitoring method in subarachnoid hemorrhage patients, and correlation with clinical events--a systematic review. J Neurol. 2003; 250:797-805. [PubMed: 12883920]

13. Bourne JA. Intracerebral microdialysis: 30 years as a tool for the neuroscientist. Clin Exp Pharmacol Physiol. 2003; 30:16-24. [PubMed: 12542448]

14. Stahl M, Bouw R, Jackson A, Pay V. Human microdialysis. Curr Pharm Biotechnol. 2002; 3:165178. [PubMed: 12022259]

15. Kett-White R, Hutchinson PJ, Czosnyka M, Boniface S, Pickard JD, Kirkpatrick PJ. Multi-modal monitoring of acute brain injury. Adv Tech Stand Neurosurg. 2002; 27:87-134. [PubMed: 11887583]

16. Hutchinson PJ, O’Connell MT, Kirkpatrick PJ, Pickard JD. How can we measure substrate, metabolite and neurotransmitter concentrations in the human brain? Physiol Meas. 2002; 23:R75109. [PubMed: 12051319]

17. Hamani C, Luer MS, Dujovny M. Microdialysis in the human brain: review of its applications. Neurol Res. 1997; 19:281-288. [PubMed: 9192381]

18. Young AM. Intracerebral microdialysis in the study of physiology and behaviour. Rev Neurosci. 1993; 4:373-395. [PubMed: 7903896]

$\bullet$ 19. Westerink Ben, HC. CTIFH. Handbook of Microdialysis: Methods, Applications and Clinical Aspects. Huston, JP., editor. Vol. 16. New York: Academic Press; 2007. Definitive comprehensive handbook of basic and clinical microdialysis

• 20. Hillered L, Persson L, Nilsson P, Ronne-Engstrom E, Enblad P. Continuous monitoring of cerebral metabolism in traumatic brain injury: a focus on cerebral microdialysis. Curr Opin Crit Care. 2006; 12:112-118. This was the previous review of cerebral microdialysis in this journal. In this accessible authoritative review, the two types of elevated $\mathrm{L} / \mathrm{P}$ ratio were defined. [PubMed: 16543785]

21. Hillered L, Persson L. Neurochemical monitoring of the acutely injured human brain. Scand J Clin Lab Invest Suppl. 1999; 229:9-18. [PubMed: 10097285]

22. Hillered L, Persson L. Microdialysis for neurochemical monitoring of the human brain. Scand Cardiovasc J. 2003; 37:13-17. [PubMed: 12745797]

23. Hlatky R, Robertson CS. Multimodality monitoring in severe head injury. Curr Opin Anaesthesiol. 2002; 15:489-493. [PubMed: 17019243]

24. Poca MA, Sahuquillo J, Mena MP, Vilalta A, Riveiro M. Recent advances in regional cerebral monitoring in the neurocritical patient: brain tissue oxygen pressure monitoring, cerebral microdialysis and near-infrared spectroscopy. Neurocirugia (Astur). 2005; 16:385-410. [PubMed: 16276448]

25. Vespa PM. Multimodality monitoring and telemonitoring in neurocritical care: from microdialysis to robotic telepresence. Curr Opin Crit Care. 2005; 11:133-138. [PubMed: 15758593]

26. Hlatky R, Contant CF, Diaz-Marchan P, Valadka AB, Robertson CS. Significance of a reduced cerebral blood flow during the first 12 hours after traumatic brain injury. Neurocrit Care. 2004; 1:69-83. [PubMed: 16174900]

27. Hlatky R, Valadka AB, Robertson CS. Intracranial hypertension and cerebral ischemia after severe traumatic brain injury. Neurosurg Focus. 2003; 14:e2. [PubMed: 15679301]

28. Robertson C. Treatment of secondary ischemic insults after traumatic brain injury. Crit Care Med. 2000; 28:3358-3359. [PubMed: 11009007] 
29. Hlatky R, Valadka AB, Goodman JC, Contant CF, Robertson CS. Patterns of energy substrates during ischemia measured in the brain by microdialysis. J Neurotrauma. 2004; 21:894-906. [PubMed: 15307902]

30. Andrews PJ. Potential end points of treatment after acute brain injury: should we be using monitors of metabolism? Curr Opin Crit Care. 2003; 9:83-85. [PubMed: 12657968]

31. Berger C, Annecke A, Aschoff A, Spranger M, Schwab S. Neurochemical monitoring of fatal middle cerebral artery infarction. Stroke. 1999; 30:460-463. [PubMed: 9933288]

32. Berger C, Xia F, Kohrmann M, Schwab S. Hypothermia in acute stroke--slow versus fast rewarming an experimental study in rats. Exp Neurol. 2007; 204:131-137. [PubMed: 17112513]

33. Bullock R, Zauner A, Myseros JS, Marmarou A, Woodward JJ, Young HF. Evidence for prolonged release of excitatory amino acids in severe human head trauma. Relationship to clinical events. Ann N Y Acad Sci. 1995; 765:290-297. discussion 298. [PubMed: 7486616]

34. Enblad P, Valtysson J, Andersson J, Lilja A, Valind S, Antoni G, Langstrom B, Hillered L, Persson L. Simultaneous intracerebral microdialysis and positron emission tomography in the detection of ischemia in patients with subarachnoid hemorrhage. J Cereb Blood Flow Metab. 1996; 16:637644. [PubMed: 8964803]

35. Frykholm P, Hillered L, Langstrom B, Persson L, Valtysson J, Enblad P. Relationship between cerebral blood flow and oxygen metabolism, and extracellular glucose and lactate concentrations during middle cerebral artery occlusion and reperfusion: a microdialysis and positron emission tomography study in nonhuman primates. J Neurosurg. 2005; 102:1076-1084. [PubMed: 16028767]

36. Goodman JC, Valadka AB, Gopinath SP, Uzura M, Robertson CS. Extracellular lactate and glucose alterations in the brain after head injury measured by microdialysis. Crit Care Med. 1999; 27:1965-1973. [PubMed: 10507626]

37. Hillered L, Kotwica Z, Ungerstedt U. Interstitial and cerebrospinal fluid levels of energy-related metabolites after middle cerebral artery occlusion in rats. Res Exp Med (Berl). 1991; 191:219_ 225. [PubMed: 1925070]

38. Kanthan R, Shuaib A, Griebel R, Miyashita H. Intracerebral human microdialysis. In vivo study of an acute focal ischemic model of the human brain. Stroke. 1995; 26:870-873. [PubMed: 7740581]

39. Kett-White R, Hutchinson PJ, Al-Rawi PG, Gupta AK, Pickard JD, Kirkpatrick PJ. Adverse cerebral events detected after subarachnoid hemorrhage using brain oxygen and microdialysis probes. Neurosurgery. 2002; 50:1213-1221. discussion 1221-1212. [PubMed: 12015838]

40. Kochs E. Monitoring of cerebral ischaemia. Acta Anaesthesiol Scand Suppl. 1997; 111:92-95. [PubMed: 9420969]

41. Langemann H, Alessandri B, Mendelowitsch A, Feuerstein T, Landolt H, Gratzl O. Extracellular levels of glucose and lactate measured by quantitative microdialysis in the human brain. Neurol Res. 2001; 23:531-536. [PubMed: 11474810]

42. Mendelowitsch A, Mergner GW, Shuaib A, Sekhar LN. Cortical brain microdialysis and temperature monitoring during hypothermic circulatory arrest in humans. J Neurol Neurosurg Psychiatry. 1998; 64:611-618. [PubMed: 9598676]

43. Nelson DW, Bellander BM, Maccallum RM, Axelsson J, Alm M, Wallin M, Weitzberg E, Rudehill A. Cerebral microdialysis of patients with severe traumatic brain injury exhibits highly individualistic patterns as visualized by cluster analysis with self-organizing maps. Crit Care Med. 2004; 32:2428-2436. [PubMed: 15599147]

44. Nilsson OG, Brandt L, Ungerstedt U, Saveland H. Bedside detection of brain ischemia using intracerebral microdialysis: subarachnoid hemorrhage and delayed ischemic deterioration. Neurosurgery. 1999; 45:1176-1184. discussion 1184-1175. [PubMed: 10549935]

45. Nilsson OG, Saveland H, Boris-Moller F, Brandt L, Wieloch T. Increased levels of glutamate in patients with subarachnoid haemorrhage as measured by intracerebral microdialysis. Acta Neurochir Suppl. 1996; 67:45-47. [PubMed: 8870801]

46. Nilsson P, Hillered L, Ponten U, Ungerstedt U. Changes in cortical extracellular levels of energyrelated metabolites and amino acids following concussive brain injury in rats. J Cereb Blood Flow Metab. 1990; 10:631-637. [PubMed: 2384536] 
47. Persson L, Valtysson J, Enblad P, Warme PE, Cesarini K, Lewen A, Hillered L. Neurochemical monitoring using intracerebral microdialysis in patients with subarachnoid hemorrhage. $\mathrm{J}$ Neurosurg. 1996; 84:606-616. [PubMed: 8613852]

48. Sarrafzadeh AS, Sakowitz OW, Callsen TA, Lanksch WR, Unterberg AW. Bedside microdialysis for early detection of cerebral hypoxia in traumatic brain injury. Neurosurg Focus. 2000; 9:e2. [PubMed: 16821754]

49. Sarrafzadeh AS, Sakowitz OW, Kiening KL, Benndorf G, Lanksch WR, Unterberg AW. Bedside microdialysis: a tool to monitor cerebral metabolism in subarachnoid hemorrhage patients? Crit Care Med. 2002; 30:1062-1070. [PubMed: 12006804]

50. Sarrafzadeh AS, Thomale UW, Haux D, Unterberg AW. Cerebral metabolism and intracranial hypertension in high grade aneurysmal subarachnoid haemorrhage patients. Acta Neurochir Suppl. 2005; 95:89-92. [PubMed: 16463827]

51. Schulz MK, Wang LP, Tange M, Bjerre P. Cerebral microdialysis monitoring: determination of normal and ischemic cerebral metabolisms in patients with aneurysmal subarachnoid hemorrhage. J Neurosurg. 2000; 93:808-814. [PubMed: 11059662]

52. Stahl N, Mellergard P, Hallstrom A, Ungerstedt U, Nordstrom CH. Intracerebral microdialysis and bedside biochemical analysis in patients with fatal traumatic brain lesions. Acta Anaesthesiol Scand. 2001; 45:977-985. [PubMed: 11576049]

53. Ungerstedt U. Microdialysis--a new technique for monitoring local tissue events in the clinic. Acta Anaesthesiol Scand Suppl. 1997; 110:123. [PubMed: 9248559]

54. Unterberg AW, Sakowitz OW, Sarrafzadeh AS, Benndorf G, Lanksch WR. Role of bedside microdialysis in the diagnosis of cerebral vasospasm following aneurysmal subarachnoid hemorrhage. J Neurosurg. 2001; 94:740-749. [PubMed: 11354405]

55. Valadka AB, Goodman JC, Gopinath SP, Uzura M, Robertson CS. Comparison of brain tissue oxygen tension to microdialysis-based measures of cerebral ischemia in fatally head-injured humans. J Neurotrauma. 1998; 15:509-519. [PubMed: 9674554]

56. Vespa $\mathrm{P}$. What is the optimal threshold for cerebral perfusion pressure following traumatic brain injury? Neurosurg Focus. 2003; 15:E4. [PubMed: 15305840]

•.57. Vespa PM. The implications of cerebral ischemia and metabolic dysfunction for treatment strategies in neurointensive care. Curr Opin Crit Care. 2006; 12:119-123. Excellent review of targeted treatment strategies for various forms of cerebral energy crisis encountered in the ICU. [PubMed: 16543786]

58. Xu W, Mellergard P, Ungerstedt U, Nordstrom CH. Local changes in cerebral energy metabolism due to brain retraction during routine neurosurgical procedures. Acta Neurochir (Wien). 2002; 144:679-683. [PubMed: 12181701]

59. Zauner A, Doppenberg EM, Woodward JJ, Choi SC, Young HF, Bullock R. Continuous monitoring of cerebral substrate delivery and clearance: initial experience in 24 patients with severe acute brain injuries. Neurosurgery. 1997; 41:1082-1091. discussion 1091-1083. [PubMed: 9361062]

60. Vespa P, Bergsneider M, Hattori N, Wu HM, Huang SC, Martin NA, Glenn TC, McArthur DL, Hovda DA. Metabolic crisis without brain ischemia is common after traumatic brain injury: a combined microdialysis and positron emission tomography study. J Cereb Blood Flow Metab. 2005; 25:763-774. [PubMed: 15716852]

•61. Dusick JR, Glenn TC, Lee WN, Vespa PM, Kelly DF, Lee SM, Hovda DA, Martin NA. Increased pentose phosphate pathway flux after clinical traumatic brain injury: a [1,2-13C2]glucose labeling study in humans. J Cereb Blood Flow Metab. 2007; 27:1593-1602. The pentose phosphate pathway may divert glucose from energy production and contribute to non-ischemic energetic distress. [PubMed: 17293841]

••62. Vespa PM, McArthur D, O’Phelan K, Glenn T, Etchepare M, Kelly D, Bergsneider M, Martin NA, Hovda DA. Persistently low extracellular glucose correlates with poor outcome 6 months after human traumatic brain injury despite a lack of increased lactate: a microdialysis study. $\mathrm{J}$ Cereb Blood Flow Metab. 2003; 23:865-877. Low extracellular glucose is a prognostic indicator of poor outcome even when frank ischemic elevation of lactate is not present. [PubMed: 12843790] 
-63. Hirsch LJ. Nonconvulsive seizures in traumatic brain injury: what you don't see can hurt you. Epilepsy Curr. 2008; 8:97-99. Review and commentary on the potential harm done by undetected and untreated nonconvulsive seizures in traumatic brain injury. [PubMed: 18596875]

••64. Vespa PM, Miller C, McArthur D, Eliseo M, Etchepare M, Hirt D, Glenn TC, Martin N, Hovda D. Nonconvulsive electrographic seizures after traumatic brain injury result in a delayed, prolonged increase in intracranial pressure and metabolic crisis. Crit Care Med. 2007 The high frequency and adverse effects on cerebral physiology and biochemistry are described.

65. Brennan KC, Beltran-Parrazal L, Lopez-Valdes HE, Theriot J, Toga AW, Charles AC. Distinct vascular conduction with cortical spreading depression. J Neurophysiol. 2007; 97:4143-4151. [PubMed: 17329631]

••66. Fabricius M, Fuhr S, Bhatia R, Boutelle M, Hashemi P, Strong AJ, Lauritzen M. Cortical spreading depression and peri-infarct depolarization in acutely injured human cerebral cortex. Brain. 2006; 129:778-790. Detailed information about the frequency and potential adverse effects of cortical spreading depression and peri-infarct depolarization in acutely injured brain is provided. [PubMed: 16364954]

67. Strong AJ, Dardis R. Depolarisation phenomena in traumatic and ischaemic brain injury. Adv Tech Stand Neurosurg. 2005; 30:3-49. [PubMed: 16350451]

68. Strong AJ, Fabricius M, Boutelle MG, Hibbins SJ, Hopwood SE, Jones R, Parkin MC, Lauritzen M. Spreading and synchronous depressions of cortical activity in acutely injured human brain. Stroke. 2002; 33:2738-2743. [PubMed: 12468763]

-69. Strong AJ, Hartings JA, Dreier JP. Cortical spreading depression: an adverse but treatable factor in intensive care? Curr Opin Crit Care. 2007; 13:126-133. Excellent review of the potentially adverse role of cortical spreading depression in the ICU with suggestions regarding therapeutic options. [PubMed: 17327732]

••70. Hashemi P, Bhatia R, Nakamura H, Dreier JP, Graf R, Strong AJ, Boutelle MG. Persisting depletion of brain glucose following cortical spreading depression, despite apparent hyperaemia: evidence for risk of an adverse effect of Leao's spreading depression. J Cereb Blood Flow Metab. 2008 Using rapid sequence microdialysis these authors demonstrate that brain extracellular glucose depletion occurs in association with cortical spreading depression and that the severity of the depletion is proportional to the number of depolarizations that occur.

71. Hartings JA, Gugliotta M, Gilman C, Strong AJ, Tortella FC, Bullock MR. Repetitive cortical spreading depolarizations in a case of severe brain trauma. Neurol Res. 2008; 30:876-882. [PubMed: 18534057]

72. Hopwood SE, Parkin MC, Bezzina EL, Boutelle MG, Strong AJ. Transient changes in cortical glucose and lactate levels associated with peri-infarct depolarisations, studied with rapid-sampling microdialysis. J Cereb Blood Flow Metab. 2005; 25:391-401. [PubMed: 15716860]

73. Folkersma H, Breve JJ, Tilders FJ, Cherian L, Robertson CS, Vandertop WP. Cerebral microdialysis of interleukin (IL)-1ss and IL-6: extraction efficiency and production in the acute phase after severe traumatic brain injury in rats. Acta Neurochir (Wien). 2008

74. Hillman J, Aneman O, Persson M, Andersson C, Dabrosin C, Mellergard P. Variations in the response of interleukins in neurosurgical intensive care patients monitored using intracerebral microdialysis. J Neurosurg. 2007; 106:820-825. [PubMed: 17542525]

•75. Hutchinson PJ, O’Connell MT, Rothwell NJ, Hopkins SJ, Nortje J, Carpenter KL, Timofeev I, AlRawi PG, Menon DK, Pickard JD. Inflammation in human brain injury: intracerebral concentrations of IL-1alpha, IL-1beta, and their endogenous inhibitor IL-1ra. J Neurotrauma. $2007 ; 24: 1545-1557$. The role of cytokines in human traumatic brain injury is an active area of investigation and these authors demonstrate the use to microdialysis in this arena. [PubMed: 17970618]

76. Mellergard P, Aneman O, Sjogren F, Pettersson P, Hillman J. Changes in extracellular concentrations of some cytokines, chemokines, and neurotrophic factors after insertion of intracerebral microdialysis catheters in neurosurgical patients. Neurosurgery. 2008; 62:151-157. discussion 157-158. [PubMed: 18300902]

77. Wang X, Lennartz MR, Loegering DJ, Stenken JA. Interleukin-6 collection through long-term implanted microdialysis sampling probes in rat subcutaneous space. Anal Chem. 2007; 79:18161824. [PubMed: 17263512] 
78. Hlatky R, Goodman JC, Valadka AB, Robertson CS. Role of nitric oxide in cerebral blood flow abnormalities after traumatic brain injury. J Cereb Blood Flow Metab. 2003; 23:582-588. [PubMed: 12771573]

79. Goodman JC, Feng YQ, Valadka AB, Bryan RJ, Robertson CS. Measurement of the nitric oxide metabolites nitrate and nitrite in the human brain by microdialysis. Acta Neurochir Suppl. 2002; 81:343-345. [PubMed: 12168342]

80. Reinert M, Zauner A, Khaldi A, Seiler R, Bullock R. Microdialysis nitric oxide levels and brain tissue oxygen tension in patients with subarachnoid hemorrhage. Acta Neurochir Suppl. 2001; 77:155-157. [PubMed: 11563276]

81. Khaldi A, Zauner A, Reinert M, Woodward JJ, Bullock MR. Measurement of nitric oxide and brain tissue oxygen tension in patients after severe subarachnoid hemorrhage. Neurosurgery. 2001; 49:33-38. discussion 38-40. [PubMed: 11440457]

82. Belli A, Sen J, Petzold A, Russo S, Kitchen N, Smith M, Tavazzi B, Vagnozzi R, Signoretti S, Amorini AM, et al. Extracellular N-acetylaspartate depletion in traumatic brain injury. $\mathrm{J}$ Neurochem. 2006; 96:861-869. [PubMed: 16371008]

83. Berger C, Kiening K, Schwab S. Neurochemical Monitoring of Therapeutic Effects in Large Human MCA Infarction. Neurocrit Care. 2008; 9:352-356. [PubMed: 18415031]

84. Li AL, Zhi DS, Wang Q, Huang HL. Extracellular glycerol in patients with severe traumatic brain injury. Chin J Traumatol. 2008; 11:84-88. [PubMed: 18377710]

85. Merenda A, Gugliotta M, Holloway R, Levasseur JE, Alessandri B, Sun D, Bullock MR. Validation of brain extracellular glycerol as an indicator of cellular membrane damage due to free radical activity after traumatic brain injury. J Neurotrauma. 2008; 25:527-537. [PubMed: 18363507]

86. Salci K, Nilsson P, Goiny M, Contant C, Piper I, Enblad P. Low intracranial compliance increases the impact of intracranial volume insults to the traumatized brain: a microdialysis study in a traumatic brain injury rodent model. Neurosurgery. 2006; 59:367-373. discussion 367-373. [PubMed: 16883177]

87. Wang Q, Li AL, Zhi DS, Huang HL. Effect of mild hypothermia on glucose metabolism and glycerol of brain tissue in patients with severe traumatic brain injury. Chin J Traumatol. 2007; 10:246-249. [PubMed: 17651596]

•88. Belli A, Sen J, Petzold A, Russo S, Kitchen N, Smith M. Metabolic failure precedes intracranial pressure rises in traumatic brain injury: a microdialysis study. Acta Neurochir (Wien). 2008; 150:461-469. discussion 470. Neurochemical signatures of metabolic failure may occur prior to elevations of intracranial pressure. [PubMed: 18421408]

••89. Samuelsson C, Hillered L, Zetterling M, Enblad P, Hesselager G, Ryttlefors M, Kumlien E, Lewen A, Marklund N, Nilsson P, et al. Cerebral glutamine and glutamate levels in relation to compromised energy metabolism: a microdialysis study in subarachnoid hemorrhage patients. $\mathrm{J}$ Cereb Blood Flow Metab. 2007; 27:1309-1317. The glutamine/glutamate cycle imposes a substantial energy demand which may not be adequately met by impaired energy metabolism in the acutely injured brain. [PubMed: 17228333]

90. Berg A, Bellander BM, Wanecek M, Gamrin L, Elving A, Rooyackers O, Ungerstedt U, Wernerman J. Intravenous glutamine supplementation to head trauma patients leaves cerebral glutamate concentration unaffected. Intensive Care Med. 2006; 32:1741-1746. [PubMed: 17001467]

•91. Miller CM, Vespa PM, McArthur DL, Hirt D, Etchepare M. Frameless stereotactic aspiration and thrombolysis of deep intracerebral hemorrhage is associated with reduced levels of extracellular cerebral glutamate and unchanged lactate pyruvate ratios. Neurocrit Care. 2007; 6:22-29. In the pendumbra adjacent to an intracerebral hemorrhage, glutamate mediated excitotoxicity may be more important than ischemia in pathogenesis. [PubMed: 17356187]

92. Soukup J, Zauner A, Doppenberg EM, Menzel M, Gilman C, Bullock R, Young HF. Relationship between brain temperature, brain chemistry and oxygen delivery after severe human head injury: the effect of mild hypothermia. Neurol Res. 2002; 24:161-168. [PubMed: 11877900]

93. Berger C, Schabitz WR, Georgiadis D, Steiner T, Aschoff A, Schwab S. Effects of hypothermia on excitatory amino acids and metabolism in stroke patients: a microdialysis study. Stroke. 2002; 33:519-524. [PubMed: 11823663] 
94. Schneweis S, Grond M, Staub F, Brinker G, Neveling M, Dohmen C, Graf R, Heiss WD. Predictive value of neurochemical monitoring in large middle cerebral artery infarction. Stroke. 2001; 32:1863-1867. [PubMed: 11486118]

95. Yamaguchi S, Nakahara K, Miyagi T, Tokutomi T, Shigemori M. Neurochemical monitoring in the management of severe head-injured patients with hypothermia. Neurol Res. 2000; 22:657-664. [PubMed: 11091969]

96. Mendelowitsch A, Sekhar LN, Caputy AJ, Shuaib A. Intraoperative on-line monitoring of cerebral pH by microdialysis in neurosurgical procedures. Neurol Res. 1998; 20:142-148. [PubMed: 9522350]

97. Farooque M, Hillered L, Holtz A, Olsson Y. Effects of moderate hypothermia on extracellular lactic acid and amino acids after severe compression injury of rat spinal cord. J Neurotrauma. 1997; 14:63-69. [PubMed: 9048312]

•98. Tisdall MM, Tachtsidis I, Leung TS, Elwell CE, Smith M. Increase in cerebral aerobic metabolism by normobaric hyperoxia after traumatic brain injury. J Neurosurg. 2008; 109:424432. These authors report improved aerobic metabolism with hyperoxia in TBI. [PubMed: 18759572]

••99. Nortje J, Coles JP, Timofeev I, Fryer TD, Aigbirhio FI, Smielewski P, Outtrim JG, Chatfield DA, Pickard JD, Hutchinson PJ, et al. Effect of hyperoxia on regional oxygenation and metabolism after severe traumatic brain injury: preliminary findings. Crit Care Med. 2008; 36:273-281. These authors report no significant improvement in aerobic metabolism with hyperoxia in TBI. [PubMed: 18090356]

••100. Diringer MN. Hyperoxia: good or bad for the injured brain? Curr Opin Crit Care. 2008; 14:167171. This editorial critically reviews the hyperoxia literature in acute neurological injury and concludes that the risk/benefit threshold has not been convincingly exceeded and that more investigation is necessary before this intervention is applied more widely. [PubMed: 18388679]

101. Vespa P, Boonyaputthikul R, McArthur DL, Miller C, Etchepare M, Bergsneider M, Glenn T, Martin N, Hovda D. Intensive insulin therapy reduces microdialysis glucose values without altering glucose utilization or improving the lactate/pyruvate ratio after traumatic brain injury. Crit Care Med. 2006; 34:850-856. [PubMed: 16505665]

••102. Oddo M, Schmidt JM, Carrera E, Badjatia N, Connolly ES, Presciutti M, Ostapkovich ND, Levine JM, Le Roux P, Mayer SA. Impact of tight glycemic control on cerebral glucose metabolism after severe brain injury: a microdialysis study. Crit Care Med. 2008; 36:3233-3238. This important paper shows potential adverse impact of tight systemic glycemic control on cerebral metabolism and outcome in TBI. Caution may be warranted in the vigor in which serum glucose is managed in the ICU. [PubMed: 18936695]

••103. Marcoux J, McArthur DA, Miller C, Glenn TC, Villablanca P, Martin NA, Hovda DA, Alger JR, Vespa PM. Persistent metabolic crisis as measured by elevated cerebral microdialysis lactatepyruvate ratio predicts chronic frontal lobe brain atrophy after traumatic brain injury. Crit Care Med. 2008; 36:2871-2877. These authors demonstrate that elevated L/P ratio acutely is associated with increased frontal lobe brain atrophy chronically after TBI. [PubMed: 18766106]

104. Bellander BM, Cantais E, Enblad P, Hutchinson P, Nordstrom CH, Robertson C, Sahuquillo J, Smith M, Stocchetti N, Ungerstedt U, et al. Consensus meeting on microdialysis in neurointensive care. Intensive Care Med. 2004; 30:2166-2169. [PubMed: 15549254]

-105. Andrews PJ, Citerio G, Longhi L, Polderman K, Sahuquillo J, Vajkoczy P. NICEM consensus on neurological monitoring in acute neurological disease. Intensive Care Med. 2008; 34:13621370. This is the most recent consensus report on neuromonitoring including microdialysis in the ICU. This conference had a broader scope than the 2004 meeting which was focused on microdialysis. This report contains useful recommendations regarding ICP monitoring, CCP targets, tissue oximetry and microdialysis. [PubMed: 18398598] 